- The wearing of cycle helmets not only reduces the incidence and severity of head and brain injuries and their long-term consequences, but also facial and some dental trauma.

- Previous assessments of helmet efficacy have focussed on mortality rates; morbidity rates, including the effects of maxillofacial and dental trauma, have been neglected.

- The dental profession could contribute significantly to promotional campaigns.

- There is scope for further research into modification of helmet design to improve facial and dental protection.

\title{
Bicycle helmets - does the dental profession have a role in promoting their use?
}

\author{
H. R. Chapman ${ }^{1}$ and A. L. M. Curran ${ }^{2}$
}

\begin{abstract}
Objectives To review the available literature regarding the: epidemiology of bicycle related head injuries; consequences of head injuries; rates of cycle helmet use; impact of educational campaigns and legislation on usage rates; effectiveness of cycle helmets in protecting against head and facial injuries; arguments against the compulsory use of bicycle helmets
\end{abstract}

Data sources A computerised Medline search was conducted using the keywords: head injury, facial injury, bicycle helmets, accidents.

Data selection All available information was considered.

Data synthesis Data was collated manually.

Conclusions The wearing of bicycle helmets contributes significantly to the prevention of head injuries (HI) and traumatic brain injury (TBI), particularly in children and adolescents.

There is evidence to support the role of cycle helmets in the prevention of injuries to the middle third of the face and some dental injuries. There is a case for the implementation of legislation accompanied by educational campaigns to increase significantly the use of cycle helmets.

The dental profession could: play an active role in promoting cycle helmet use; support calls for the compulsory wearing of cycling helmets, particularly for children; press for modification of helmet design and standards to increase protection of the face.

In the UK in 1973, as a result of mounting evidence about their effectiveness in preventing injury and death, the wearing of helmets on motorbikes and scooters was made compulsory. Following extensive campaigns to promote the voluntary use of car seat belts, such as 'clunk click every trip', usage rates were still so low that in 1983, legislation was enacted to make the use of vehicle front seat belts compulsory. Then, in 1989, the use of rear seat belts became compulsory for children under 14 years old and in 1991 for all rear passengers. There were protests about the introduction of these measures, but they are now an accepted fact and enforced by the police.

${ }^{1 *}$ Registered Specialist in Paediatric Dentistry, 6 Woodlands Way, Southwater, Horsham, W Sussex RH13 9HZ; ${ }^{2}$ Consultant Paediatric Neurologist, Alder Hey Children's Hospital, Eaton Road, Liverpool L12 2AP

*Correspondence to: Helen Chapman, 8 Millais Court, Manor Fields, Horsham, W Sussex RH13 6SJ

Email:helen.chapman@tesco.net

\section{Refereed Paper}

Received 02.08.02; Accepted 05.02.04

doi:10.1038/sj.bdj.4811227

(๑) British Dental Journal 2004; 196: 555-560
So far, in the UK, calls for the compulsory use of bicycle helmets have been resisted, although other countries such as New Zealand and Australia have legislation in place.

In this article we review the literature surrounding the impact of head injury on the individual child and how wearing bicycle helmets can affect the outcome following an accident whilst riding a bicycle.

\section{EPIDEMIOLOGY OF HEAD INJURY AFTER BICYCLE ACCIDENTS}

Across all ages in the UK it is estimated that there are 90,000 roadrelated and 100,000 off-road cycling accidents per year. ${ }^{1}$ Of these accidents, 100,000 (53\%) involved children under 16, suggesting that children are at greater risk of injury during cycling than adults.

In the UK, there were between 127 and 203 cycling fatalities per year between 1996 and 2002,,3 of which 70-80\% were caused by traumatic brain injury (TBI). ${ }^{1}$ The most recent Government death and serious injury figures ${ }^{2}$ are summarised in Table 1. In children under 16, two-thirds of cycle-related deaths occur in road traffic accidents (RTAs) with the remaining third occurring whilst the child is cycling off road. The majority of injuries, however, occur when children are cycling off road ${ }^{3-6}$ and, of these, traumatic brain injury (TBI) is the most likely to have long-term consequences. ${ }^{7,8}$

Boys are at much greater risk than girls: for example, ${ }^{9,10}$ the reported accident ratio of boys to girls varying between $2: 1^{11}$ and $4: 1 .^{12}$ Even when the extra hours spent cycling by boys are taken into account they are still at increased risk, probably caused by greater risk-taking behaviour. ${ }^{9}$ The highest overall injury and TBI death rates are amongst 10-15-year-olds, particularly boys. ${ }^{12}$ Young children are not however free of risk. Fifty-nine per cent of children aged 1-5 years having accidents with bicycles, tricycles and other wheeled toys had head injuries ${ }^{6}$ and the use of children's bike carriers also puts this age group at risk of TBI. ${ }^{11}$

All the studies quoted thus far rely on hospital accident and emergency statistics and, although they are likely to include children with more serious injuries, may under-represent the whole picture for two reasons. First, head injuries, especially mild events, are significantly more difficult to diagnose in children $^{5}$ and are even more likely to go under-recognised ${ }^{12}$ or recorded and thus be under-represented in accident statistics and retrospective research. Secondly, children sustaining a 'mild bump on the head' may well not attend hospital. ${ }^{5}$ Evidence is now emerging that even injuries this 'trivial' in pre-school chil- 


\begin{tabular}{|c|c|c|c|c|c|c|c|c|}
\hline & & \multicolumn{6}{|c|}{ Number of casualties } & \multirow[b]{2}{*}{2002} \\
\hline & & 1996 & 1997 & 1998 & 1999 & 2000 & 2001 & \\
\hline \multicolumn{9}{|l|}{ Totals (All ages) } \\
\hline Killed & & 203 & 183 & 158 & 172 & 127 & 138 & 130 \\
\hline $\mathrm{KSI}^{*}$ & & 3,789 & 3,592 & 3,312 & 3,367 & 2,770 & 2,678 & 2,450 \\
\hline All severities of injury & & 24,584 & 24,636 & 22,923 & 22,840 & 20,612 & 19,114 & 17,107 \\
\hline \multicolumn{9}{|l|}{$K S I^{*}$ byage } \\
\hline & 0 to 4 & 21 & 15 & 18 & 21 & 9 & 8 & 8 \\
\hline & 5 to 7 & 148 & 136 & 120 & 137 & 81 & 66 & 66 \\
\hline & 8 to 11 & 423 & 354 & 281 & 302 & 254 & 212 & 193 \\
\hline & 12 to 15 & 639 & 511 & 496 & 490 & 414 & 388 & 327 \\
\hline & 16 to 19 & 365 & 352 & 324 & 281 & 204 & 229 & 178 \\
\hline & 20 to 24 & 321 & 288 & 279 & 244 & 203 & 198 & 170 \\
\hline & 25 to 59 & 1,524 & 1,562 & 1,484 & 1,389 & 1,337 & 1,279 & 1,233 \\
\hline & 60 and over & 307 & 340 & 258 & 258 & 210 & 245 & 220 \\
\hline & All age groups & 3,789 & 3,592 & 3,312 & 3,367 & 2,770 & 2,678 & 2,450 \\
\hline
\end{tabular}

${ }^{*} \mathrm{KSI}=$ Killed and seriously injured

dren can result in long lasting cognitive deficits, such as difficulties with literacy when they start to attend school. ${ }^{13}$ For example, children aged 2.5 to 4.5 who had had a mild head injury which did not warrant admission, showed no reading related-skills deficits initially, but did so at 6 and 12 months follow-up. At 6.5 years old they showed problems with reading, more requiring remedial help; thus it was the further development of the skill which was affected.

\section{THE INCIDENCE OF MAXILLOFACIAL INJURY IN BICYCLE ACCIDENTS}

Studies in Australia have shown that 23-25\% of children under 15 sustained facial injuries in bicycle accidents. ${ }^{15,16}$ In the UK, a study ${ }^{11}$ of 948 children involved in cycle accidents found that $46 \%$ of the under fives, 25\% of 5-9 year olds and 8\% of 11-16 year olds had facial injuries. The very high rate of facial injuries in preschool children may be because the wheels on their 'vehicles'/bicycles are small in diameter. Thus, if an obstruction such as a stone is hit, the 'vehicle' is likely to stop abruptly sending the child's head forward so that the face impacts with the handlebars or steering wheel. Cycle helmets do not always protect from this type of injury. In one of the Australian studies ${ }^{16}$ it was found that $50 \%$ of these children had been wearing a standard cycle helmet.

Sex and age differences are also observed in the incidence and type of facial injuries seen following cycling accidents. Boys sustain more facial injuries than girls eg reference 11.
The overall rate of mouth injuries is reported as 4\% in people younger than $20^{6}$ and in the youngest children (1-5-year-olds) the mouth is involved in $11 \%$ of cases. ${ }^{6,11}$

Thirty one per cent of those with facial injuries had a dental injury. ${ }^{16}$ Many children with dental injuries will not be represented in the hospital statistics as they may only be taken to see the dentist. $6,16,17$

\section{THE OUTCOME OF HEAD INJURY}

Head injuries are defined as involving damage to the skull (simple or depressed fracture, penetrating injuries) and/or lacerations to the scalp or forehead. Some studies include damage to the face and facial skeleton, but there is an increasing trend to consider the areas separately. ${ }^{18}$

A head injury may or may not be associated with a traumatic brain injury. TBI ranges from serious injuries such as subdural haematomas, brain contusions and diffuse axonal injury to mild diffuse brain injury. A closed head injury may result in diffuse brain damage ${ }^{19}$ which is not visible on the radiographs used to diagnose bony fractures and is often not apparent on CT scanning either. ${ }^{20}$ Therefore this type of injury often goes undiagnosed at time of admission and problems arising from it may only become apparent later. The lack of neurological investigation of most individuals following head injuries and the fact that detailed imaging has only become available in the recent past and is still rarely used, means that a lot of the research on the effects of TBI has to rely on 'head injury' as a substitute vari-

Table 2 Rates of Long-term disabilities after head injuries

\begin{tabular}{|c|c|c|c|c|c|}
\hline \multirow[t]{2}{*}{ Study } & \multirow{2}{*}{$\begin{array}{l}\text { Severity of injury } \\
\text { (assessment criteria) }\end{array}$} & \multicolumn{4}{|c|}{ Level of recovery \% } \\
\hline & & $\begin{array}{l}\text { Dead or } \\
\text { vegetative state }\end{array}$ & $\begin{array}{l}\text { Severe disability } \\
\text { (unable to } \\
\text { support self for } \\
24 \text { hrs in society) }\end{array}$ & $\begin{array}{l}\text { Moderate disability } \\
\text { (significant restrictions } \\
\text { in lifestyle and/ } \\
\text { or work capacity) }\end{array}$ & $\begin{array}{l}\text { Good recovery } \\
\text { (resumption of } \\
\text { previous lifestyle) }\end{array}$ \\
\hline Thornhill et al. ${ }^{22}$ & Mild (GCS 13-15) & 8 & 20 & 28 & 45 \\
\hline Adolescents/ & Moderate (GCS 9-12) & 16 & 22 & 24 & 37 \\
\hline adults 14+ & Severe (GCS 3-8) & 38 & 29 & 19 & 10 \\
\hline $\begin{array}{l}\text { Deb et al. }{ }^{23} \\
\text { Adults } 17+\end{array}$ & $\begin{array}{l}\text { Mild (GCS 13-15) } \\
\text { and/or loss of consciousness/ } \\
\text { skull fracture/cerebral } \\
\text { haemorrhage/contusion }\end{array}$ & 0 & 2.9 & 25.5 & 69.3 \\
\hline
\end{tabular}


Table 3 The reduction in head injury after some educational campaigns

\begin{tabular}{llr}
\hline Study & Measure & Percentage reduction (\%) \\
\hline Takriti et al. ${ }^{39}$ UK 1999 & Hospital admission for head injury & 45 \\
\hline Lee et al. ${ }^{4}$ UK 2000 & Head injury & 9 \\
\hline Cited in Ref. 38 & Hospital admission for head injury & 40 \\
\hline McDermott ${ }^{12}$ Aus 1995 & Overall head injury & 16 \\
\hline Rivara Reviews ${ }^{36,37}$ USA 1994/1998 & Head injury admissions 5-9 year olds & 67 \\
& Head injury admissions 10-14 year olds & 68
\end{tabular}

able in data analysis, with trauma to the brain being inferred as the cause of the subsequent problems.

For prognostication purposes, the severity of TBI is usually measured by admission Glasgow Coma Score (GCS), ${ }^{21}$ length of coma $^{19}$ and duration of post-traumatic amnesia (PTA). ${ }^{21}$

As has already been mentioned, traumatic brain injury (TBI), of all the injuries likely to be sustained by a cycling accident, is the most likely to cause long-term damage. ${ }^{1,7}$ Outcomes from TBI range from death through significant levels of permanent disability ie hemiplegia, communication problems (hearing, vision, speech), epilepsy, headaches, dizziness, sleep disturbance and poor concentration to increased emotionality, impulsivity and aggression. ${ }^{21-23}$

These can impact on day-to-day activities, relationships and educational and earning potential. ${ }^{23,24}$ The psychiatric consequences of even mild head injuries can be psychiatric illness ${ }^{23}$ and increased rates of suicide. ${ }^{26}$ There is now evidence that these effects are noticeable throughout adult life ${ }^{26}$ and that a head injury may be associated with an increased risk of developing Alzheimer's disease and other dementias. ${ }^{27,28}$

Table 2 summarises two studies ${ }^{22,25}$ on the outcome of head injuries. It is worth highlighting that, of the individuals with an initial diagnosis of 'mild head injury':

1. Death or vegetative state occurred in up to $8 \%$ of cases, and

2. Between $28.3 \%$ and $48 \%$ of individuals were left with permanent moderate or severe levels of disability.

This represents a significant level of personal tragedy and a severe long-term burden on social and healthcare services.

In adults, the maximum effect of a brain injury is usually seen immediately and diminishes with time as some 'rewiring' of the neural network takes place. In children, where the brain is still developing, the reverse can be true, resulting in long-lasting effects. These effects appear to be time sensitive ie the time of injury influences the type of academic skill deficit and may influence its severity. ${ }^{25}$

\section{THE CASE FOR BICYCLE HELMETS}

McDermott, ${ }^{12}$ in Australia, reported that, in a sample of 830 cyclists, the first objects struck by the face, head or helmet were the ground and then motor vehicles. The road and vehicles were also the most common objects of impact for any part of the body. This suggests that in an accident the initial collision, and thus the brunt of the impact, is often taken by the head.

\section{How do helmets work?}

When the head impacts with a hard surface as, for example in a fall from a bicycle, it decelerates rapidly. This deceleration can cause cerebral contusions as the brain hits the skull and/or diffuse axonal injuries as a result of tearing and shearing within the substance of the brain. ${ }^{29}$ These can result in temporary or permanent brain damage.

A helmet distributes the kinetic energy of the impact over a wider area and thus reduces the rate of deceleration and risk of TBI.
By spreading the impact energy over a greater area, direct trauma such as skull fractures are prevented. The helmet also works by preventing penetrating injuries such as from stones. ${ }^{4}$

\section{Do helmets really work?}

A Transport Research Laboratory hospital-based study ${ }^{1}$ estimated that if unhelmeted riders had been wearing helmets, 30\% of the slightly injured and 11\% of the seriously injured would not have been injured at all and 18\% of the seriously injured would have sustained only minor injuries.

Cook and Sheikh ${ }^{8}$ reviewed the UK trends in serious head injuries (skull fractures and intracranial injuries) in cycle accidents between 1991 and 1995, a period when cycle helmet use was reportedly increasing. During this period, the total number of emergency admissions of cyclists changed very little, but the number with head injury as the primary diagnosis, fell by around 25\% and there was a reduction in admission for head injury from $40 \%$ to $28 \%$ of bicycle accident cases. This reduction was evenly spread across the age groups (9\% in 6-10-year-olds, 11\% in 11-15-yearolds and $13 \%$ in adults; $16+$ ).

Thompson et al. ${ }^{30}$ examined the effect of helmet wearing in 3,990 injured cyclists who were admitted to hospital during an 18-month period. Of the 14 fatalities, 13 were unhelmeted and the deaths of 11 individuals were attributed to head injury. A study in Newcastle also reported that all 33 of the child cyclist fatalities due to head injury during the course of the study were in unhelmeted cyclists. ${ }^{31}$

Studies assessing the effectiveness of cycle helmet educational campaigns show reductions in total head injuries and significant reductions in admission for head injury (Table 3). This suggests that helmets have a significant impact in reducing the severity of the more serious head injuries; although riders are still recorded as sustaining head injuries, these are then not serious enough to warrant hospital admission. The larger reduction in hospital admissions in the USA may be due to more highly effective campaigns or to a lower, more cautious threshold for hospital admission following head injury, which would result in a proportionately greater reduction in admissions.

An Australian study found that facial injuries were reduced by $28 \%$ and also reduced in severity in helmeted riders. ${ }^{32}$ In 1990 Thompson et al., ${ }^{33}$ concluded that the use of a cycle helmet conferred a protective effect of 73\% for injuries to the upper face (forehead, orbit, eyes and ears). In a subsequent study, ${ }^{34}$ this group found that the use of a helmet significantly reduced the incidence of upper (as above) and middle face (nose, cheeks, zygoma and maxilla) injuries, but not that of lower face (lips, intra-oral region and lower jaw) injuries. Dental injuries were specifically excluded, but it might be reasonable to surmise that a helmet that confers protection to the nose and maxilla is likely to confer some degree of protection to the upper dentition. ${ }^{17}$

There have been two reviews of the literature on the effectiveness of cycle helmets in reducing head and brain injury rates in cyclists. The later meta-analysis ${ }^{35}$ considered all case control tri- 


\begin{tabular}{|c|c|c|}
\hline \multirow[t]{2}{*}{ Type of Injury } & \multicolumn{2}{|c|}{$\begin{array}{l}\text { Reduction in risk of injury when } \\
\text { wearing cycle helmet (\%) }\end{array}$} \\
\hline & Meta analysis ${ }^{25}$ & Cochrane review ${ }^{18}$ \\
\hline Head (scalp, skull or brain) & 45 & 85 \\
\hline $\begin{array}{l}\text { Brain (loss of consciousness/evidence of brain injuryl } \\
\text { dysfunction resulting from trauma) }\end{array}$ & 33 & 88 \\
\hline Serious brain (abbreviated injury score $3+$ ) & & 85 \\
\hline Facial (fracture/laceration) including lower face & 27 & \\
\hline Serious facial & & 19 \\
\hline Fatal & 29 & \\
\hline \multicolumn{3}{|l|}{ Summarystatistics } \\
\hline Protective effect of wearing helmet in crash with motor vehicle & & 69 \\
\hline Protective effect of wearing helmet in all other crashes & & 68 \\
\hline
\end{tabular}

als published since 1987 . The Cochrane Review ${ }^{18}$ was more selective, considering only prospective case-control studies that met rigorous inclusion criteria. Five studies conducted between 1989 and 1996 (one in the UK, one in Australia and three in the USA) were included. The results of these two analyses are summarised in Table 4.

\section{How can we improve helmet usage?}

Some studies reporting the rates of cycle helmet use pre- and posteducation campaigns and post-legislation are summarised in Table 5.

In their review of educational programmes, Rivara et al. ${ }^{36,37}$ found that educational programmes resulted in an increase in observed helmet use of between $19 \%$ and 52\%, but compliance never approached 100\%.

Local experience seems to have a bearing on helmet wearing. Whilst a study was being conducted in Canada into the effects of a promotional campaign for helmet wearing, a child cyclist in one of the towns involved suffered a fatal accident whilst cycling. Following this it was found that the cycling population in the town were five times more likely to wear their helmets than the cycling population in the control town. Even so, helmet use never exceeded 50\%.38
But, in Australia and New Zealand, where legislation followed educational campaigns, compliance rates increased to up to $95 \%$ from wearing rates as low as $2 \% .{ }^{12}$ In their review of "helmets, education and legislation', Rivara et al. ${ }^{36}$ state that this is the most acceptable and efficacious method of introducing compulsory use, as it creates 'grass roots support'.

\section{What is the economic cost of non-helmet wearing?}

As a public health argument, the compulsory use of bicycle helmets can be viewed as a logical extension of the use of motorbike helmet and front and rear seatbelts. The Bicycle Helmet Initiative Trust ${ }^{39}$ has published a basic cost-benefit analysis of their helmet promotion campaign in West Berkshire (total population 450,000; 0-15 years population 120,000). The educational programme (which is of proven effectiveness) cost, for a school population of $100,000, £ 23,000$ for the initial year and £16,000 per annum thereafter. They estimated that, in 1997, the use of helmets by injured cyclists reduced inpatient care costs by $£ 291,703$. Using loss of life potential and the 'willingness to pay' approach, an attempt was also made to quantify the indirect cost of the accidents. The costing reflected human cost (pain, suffering, grief); medical costs and direct economic cost eg loss of output. The calculations did not

Table 5 The effect of educational campaigns and legislation on the rate of wearing of bicycle helmets

\begin{tabular}{|c|c|c|c|c|c|}
\hline \multirow[b]{2}{*}{ Study } & \multirow[b]{2}{*}{ Type of sample } & \multicolumn{4}{|c|}{ Approximate percentage of cyclists wearing helmets $(\%)$} \\
\hline & & Pre-education & Post-education & Pre-legislation & Post-legislation \\
\hline \multirow[t]{3}{*}{ McDermott ${ }^{12}$ Australia } & Primary school & 5 & 72 & & 92 \\
\hline & Secondary school & 2 & 11 & & 42 \\
\hline & Adult & 25 & 50 & & 92 \\
\hline Caplow and Runyan ${ }^{45} \mathrm{NZ}$ & All children & & & 54 & 95 \\
\hline \multirow{3}{*}{$\begin{array}{l}\text { Robinson }{ }^{46} \text { (Victoria, Aus) } \\
\text { (New South Wales, Aus) }\end{array}$} & All ages & & & 31 & 67 \\
\hline & All children & & & 31 & 76 \\
\hline & Adults & & & 26 & 85 \\
\hline Sacks et al. ${ }^{47}$ USA & All children & & & 25 & 49 \\
\hline \multirow[t]{3}{*}{ Scuffham and Langley ${ }^{43} \mathrm{NZ}$} & Primary school & & 84 & & \\
\hline & Secondary school & & 62 & & \\
\hline & All children & & 39 & & \\
\hline Lee et al. ${ }^{4}$ UK & Secondary school & 11 & 31 & & \\
\hline Quine et $a l^{10} \mathrm{UK}$ & Secondary school & $\begin{array}{c}0 \\
\text { (targeted } \\
\text { at non-wearers) }\end{array}$ & 25 & & \\
\hline
\end{tabular}


appear to include the cost of consequent special educational needs provision. The report concluded that the estimated total savings over the 10-year period of the helmet-promotion programme (without special education provision) was £4.2 million.

\section{THE CASE AGAINST HELMETS}

The hypothetical arguments against the use of cycle helmets are focused on:

\section{Helmet use being associated with an increase in neck injuries} because of:

- The helmet increasing head rotation, and

- Older-style helmets without a shell dragging rather than sliding along the ground.

The Cochrane Reviewers ${ }^{18}$ found no evidence for either of these arguments among the bicycle helmet studies or among research into motorcyclists.

2. Wearing a helmet makes the rider feel more secure and therefore increases risk taking. ${ }^{32}$

The case against this, again summarised in the Cochrane Review, ${ }^{18}$ is that there is variable evidence of increased risk taking in car drivers and motor-bikers following compulsory use of seat belts/ helmets and that there has been no systematic review. Indeed, the authors quote the example of the repeal of legislation requiring compulsory motorbike helmet use in the USA; it was followed by a $25 \%$ increase in accident-related deaths. The other point which the authors make to refute this argument is that, as helmet wearing reduces the risk of serious head/brain injury by more than $80 \%$, then cyclists would have to increase their risk-taking behaviour four-fold to negate the benefits of helmet use.

3. Individuals who wear helmets are more cautious and are therefore less likely to be involved in accidents and sustain less serious injuries, thus distorting the accident figures. ${ }^{40}$

One paper $^{41}$ specifically tried to evaluate whether wearing a helmet had an impact on other injuries sustained and found no difference between the two groups, which should have been the case if helmeted riders felt safer and took more risks. The total number of emergency admissions of cyclists across the period of another study ${ }^{8}$ changed very little (1991-2, 8,678: 1994-5, 8,781 ), but head injuries fell, suggesting no change in cyclists' risk taking behaviour.

4. That compulsory use of helmets deters people from cycling, ${ }^{12,42}$ particularly adolescents.

However, some work has shown an increase in adult riding (cited in ref. 43) after legislation. Longer-term follow-up studies ${ }^{18}$ suggest that after some time has passed, wearing and riding rates increase again.

A paper much quoted by the anti-legislation lobby is that of Hillman ${ }^{42}$ that suggests that the promotion of bicycle helmets is not cost-effective. This is based on actuarial data comparing life years lost by cyclists in road traffic accidents and life years gained by cycling. (Cyclists who ride at least $40 \mathrm{~km}$ each week may halve their risk of heart disease compared with those who do not cycle.) The BMA's Board of Education and Science used these arguments when concluding not to recommend the compulsory use of cycle helmets. ${ }^{43}$ Reliance on death rates to compute this type of cost/benefit figure is misleading as it fails to take into account any of the physical, mental and social morbidities that can be caused by even quite mild head injuries and the cost to the State of special education and employment provision and of supporting families as a result of relationship breakdowns secondary to head injury. ${ }^{23-25,44}$

\section{CONCLUSIONS}

This review of the literature, shows that the case made against the wearing of bicycle helmets is weak, relying on:

- Assertions which are not borne out by research studies and

- On cost-effectiveness analysis of mortality, not morbidity, statistics.

Cycling accidents, on- and off-road, result in a significant number of HIs and TBI-related deaths and disability in children and adults. The use of bicycle helmets significantly decreases the severity of TBI and HI and actually prevents many mild injuries, yet there is still a very low rate of helmet wearing among adults and children. Experience in other countries suggests that education is not enough to change the helmet-wearing behaviour of the majority of the bicycle riding population and that legislation is necessary to significantly increase rates of use.

The literature shows that wearing cycle helmets is a simple preventative behaviour which has significant implications for public and individual health, impacting as it does on the number of deaths from trauma, the severity of injury, the number of hospital admissions and on post-accident morbidity with further implications for rehabilitation, supported living, educational problems, reduced employment prospects and poorer mental health. All these potentially avoidable stigmata carry significant costs for the NHS and education services.

As dentists, we are particularly interested in the face. With current helmets there is a weaker, though noticeable, reduction in the risk of middle third facial injuries. We also have frequent contact with the childhood population. We should therefore be lobbying for improvements in design as well as increased use.

Helmet wearing is a simple, single-point-of-entry intervention which has been shown to be cost effective. We would suggest that legislation would be hastened by a unified call from all interested/ involved healthcare professionals including the dental profession. 'A unified display in hospital units, casualty departments, health centres, dentists' waiting rooms and schools could bring about greater awareness and more encouragement of helmet use.' ${ }^{1}$

The authors would like to thank the anonymous peer reviewer for his/her detailed and constructive comments on a previous version of this paper.

\section{Appendix}

If you would like further information on head injuries please contact Headway - the brain injury association at: 4 King Edward Court, King Edward Street, Nottingham, NG1 1EW, England. Tel 0115924 0800, Fax 01159584446 Email:enquiries@headway.org.uk,websitewww.headway.org.uk

If UK readers would like promotional material including vouchers for subsidised cycle helmets, please contact The Bicycle Helmet Initiative Trust at 6 Arkwright Road, Reading, Berkshire, RG2 OLU, England. Tel 01189583585 Fax 0118956 8424, email: BHIT@Dial.Pipex.com, website www.BHIT.Org

1. Mann N P, Lee A J. Bicycle helmets: their role in injury prevention. Curr Paediatr 1999; 9: $173-1766$

2. Road Accidents Great Britain: 2000 - The Casualty Report. Department of Transport Local Government and the Regions, London 2001

3. Road Accidents Great Britain:2002 -The Casualty Report. Department of Transport Local Government and the Regions, London 2003

4. Lee A J, Mann N P, Takriti R. A hospital led promotion campaign aimed to increase bicycle helmet wearing among children aged 11-15 living in West Berkshire 1992-98. Injury Prevention 2000; 6: 151-153.

5. Jennett B. Some international comparisons. In H S Levine, H M Eisenberg, A L Benton (eds). Mild Head Injury. New York: Oxford University Press, 1989, pp23-34 cited in Satz P, Zaucha K, McCleary C, Light R, Asarnow R, Becker,D. Mild head injuries in children and adolescents: A review of studies (1970-1995). Psychol Bull 1997; 122: 107-131.

6. Sosin S M, Sacks J J, Webb K W. Pediatric head injuries and deaths from bicycling in the United States. Pediatrics 1996; 98: 868-870.

7. Li G, Baker SP, Fowler C, DiScala C. Factors related to the presence of head injury in bicycle-related pediatric trauma patients. J Trauma:Injury, Infection Critical Care 
1995; 38: 871-875

8. Cook A, Sheikh A. Trends in serious head injuries among cyclists in England: analysis of routinely collected data. Br Med J 2000; 321: 1055

9. Takriti R, Lee A J. An analysis of teenage attitudes towards bicycle helmet wearing Reading, UK. The Bicycle Helmet Initiative Trust 2000, BHIT report No 1125.

10. Quine L, Rutter D R, Arnold L. Persuading school-age cyclists to use safety helmets: Effectiveness of an intervention based on the theory of planned behaviour. Br J Health Psychol 2001; 6: 327-345.

11. Lee A J, Takriti R. Pedal cycle injuries among the under sixteens and the possible effect of helmets in reducing head injury Reading, UK. The Bicycle Helmet Initiative Trust 2000, BHIT report No 1120

12. McDermott F. Bicyclist head injury prevention by helmets and mandatory wearing legislation in Victoria, Australia. Ann R Coll Surg Eng 1995; 77: 38-44.

13. Moss N E G, Wade D T. Admission after head injury: how many occur and how many are recorded? Injury 1996; 27: 159-161.

14. Wrightson P, McGinn V, Gronwell D. Mild head injury in preschool children: evidence that it can be associated with a persisting cognitive defect. J Neurol, Neurosurg Psychiatry 1995; 59: 375-380.

15. Acton C H C, Thomas S Nixon J W, Clark R Pitt, W R, Battistutta D. Children and bicycles: what is really happening? Studies of fatal and non-fatal bicycle injury. Injury Prevention 1995; 1: 86-91.

16. Acton C H C, Nixon J W, Clark R C. Bicycle riding and oral/maxillofacial trauma in young children. Med J Aust 1996; 165: 249-251.

17. Harrison M G, Shepherd J P. The circumstances and scope for prevention of maxillofacial injuries in cyclists. J R Coll Surg Edin 1999; 44: 82-86.

18. Thompson D C, Rivara FP, Thompson R. Helmets for preventing head and facial injuries in bicyclists (Cochrane Review) In The Cochrane Library, Issue 3, 2001. Oxford: Update Software.

19. Wiederholt W C. Neurology for non-neurologists. 4th ed Philadelphia: WB Saunders and Co, 2000, pp297-304.

20. Talamonti G, Fontana P P, Versari F, et al. Delayed complications of ethmoid fractures: a 'growing fracture' phenomenon. Acta Neurochirurgica 1995; 137: 164-173.

21. Marsden C D, Fowler T J. Clinical Neurology 2nd ed. London: Arnold, 1998, pp272 282.

22. Thornhill S, Teasdale G M, Murray G D, McEwen J, Roy C W, Penny K I. Disability in young people and adults one year after head injury: prospective cohort study. Br Med J 2000; 320: 1631-1635.

23. Deb S, Lyons I, Koutzoukis C Nueropsychiatric sequelae one year after a minor head injury. J Neurol Neurosurg Psychiatry 1998; 65: 899-902.

24. Bogan A M, Livingston M G, Parry-Jones W L I, Buston K M, Wood S F. The experiential impact of head injury on adolescents: individual perspectives on long-term outcome. Brain Injury 1997; 11: 431-443

25. Teasdale TW, Engberg A W. Suicide after traumatic brain injury: a population study. J Neurol Neurosurg Psychiatry 2001; 71: 436-440.

26. Holsinger T, Steffens D C, Phillips C, Helms M J, Havlik J J, Breitner J C S, Guralnik J M Plassman B L. Head injury in early adulthood and the lifetime risk of depression. Arch Gen Psychiatry 2002; 59: 17-22.

27. Plasman B L, Havlik R J, Steffens D C et al. Documented head injury in early adulthood and risk of Alzheimer's disease and other dementias. Neurology 2000; 55: 1158-1166. 28. Mortimer J A, van Duijn C M, Chandra V et al. For EUROODERM Risk factors research group head trauma as a risk factor for Alzheimers disease: a collaborative re-analysis of case-control studies. Int J Epidemio/ 1991; 20(suppl 2): S28-35

29. Ommaya A K. Head injury mechanisms and the concept of prevention management: A review and critical synthesis. J Neuro Trauma 1995; 12: 527-546.

30. Thompson D C, Rivara FP, Thompson R S. Effectiveness of bicycle safety helmets in preventing head injuries. JAm Med Assoc 1996; 276: 1968-1973.

31. Sharples P M, Storey A, Aynsley-Green A et al. Causes of fatal childhood accidents involving head injury in northern region 1979-86. Br Med J 1990; 301: 1193-1197.

32. McDermott F T, Lane J C, Brazenor G A, Debney E A. The effectiveness of bicyclist helmets: a study of 1,710 casualties. JTrauma 1993; 34: 834-845.

33. Thompson D C, Thompson R S, Rivara FP, Wolf M E. A case-control study of the effectiveness of bicycle safety helmets in preventing facial injury. Am J Public Health 1990; 80: 1471-1474.

34. Thompson D C, Nunn M E, Thompson R S, Rivara F. Effectiveness of bicycle safety helmets in preventing serious facial injury. J Am Med Assoc 1996; 276: 1974-1975

35. Attewell R G, Glase K, McFadden M. Bicycle helmet efficacy: a meta-analysis. Accid Anal Prev 2001; 33: 345-352.

36. Rivara FP, Thompson D, Patterson M Q, Thompson R S. Preventions of bicycle-related injuries: Helmets, Education and Legislation. Annu Rev Public Health 1998; 19: 293-318.

37. Rivara F P, Thompson D C, Thompson R S, Rogers L W, Alexander B et al. The Seattle children's helmet campaign: changes in helmet use and head injury admissions. Pediatrics 1994; 93: 567-569.

38. Rourke L L. Bicycle helmet use among children. Impact of a community education programme and a cycling fatality. Can Fam Physician 1994; 40: 1116-1124.

39. Takriti R, Lee A. Initiating a bicycle helmet programme aimed at the under 16 age group - A cost benefit analysis for health authorities and trusts. The Bicycle Helmet Initiative Trust; Reading, UK, 1999.

40. Spaite D W, Murphy M, Criss E A, Valenzuela T D, Meislin H W. A prospective analysis of injury severity among helmeted and non-helmeted bicyclists involved in collisions with motor vehicles. J Trauma 1991; 31: 1510-1516.

41. Maimaris $C$, Summers C L, Browning $C$, Palmer CR. Injury patterns in cyclists attending an accident and emergency department: a comparison of helmet wearers and non-wearers. Br Med J 1994; 308: 1537-1540.

42. Hillman M. Cycling offers important health benefits and should be encouraged. $B$ Med J 1997; 315: 490.

43. Scuffham PA, Langley J D. Trend in cycle injury in New Zealand under voluntary helmet use. Accid Anal Prev 1997; 29: 1-9.

44. Cycle Helmets. London: BMA Board of Science and Education, 1999.

45. Caplow M P, Runyan CW. Parental responses to a child bicycle helmet ordinance. Am J Prev Med 1995; 11:371-374.

46. Robinson D L. Head injuries and bicycle helmet laws. Accid Anal Prev 1996; 28 : 473-475.

47. Ni H, Sacks J J, Curtis L, Cieslak P R, Hedburg K. Evaluation of a statewide bicycle helmet law via multiple measures of helmet use. Arch Pediatr Adolesc Med 1997 151: 59-65. 